\title{
Research on Computer Lab Management Mode based on Internet of Things
}

\author{
Guoxing Shi
}

Yunnan Minzu University School of Mathematics and Computer Science, Kunming, Yunnan, 650504, China

Keywords: Internet of Things; computer lab; management model

\begin{abstract}
With the continuous advancement and reform of education, experimental teaching has been widely used in colleges and universities. In order to cultivate students' innovative thinking, the application of this method has opened up a new model of computer lab teaching. Compared with the previous computer lab management mode, it shows the advantages of the IoT computer lab management mode. This paper will conduct in-depth research and analysis on the management model of the Internet of Things computer lab, and make a detailed summary.
\end{abstract}

\section{Introduction}

The role of the computer lab is to test the student's computer level and teaching level, and to improve the computer's ability to operate and create thinking skills. In recent years, computer lab education in colleges and universities has received much attention. In order to improve the teaching quality of computer labs, it is the most basic condition to improve the construction and management of computer labs. At present, the computer labs in colleges and universities in China are subject to heavy teaching tasks. Therefore, in the process of using computers, it is difficult to use fixed machines. Students often change different computers, which may cause students and teachers to operate uncomfortable. Standardize operations. In addition, in the computer laboratory management, most of them are not responsible for the person, so the use, maintenance and failure of the computer can not be solved in a timely manner, affecting the teaching tasks, and thus affecting the quality of students' learning. With the emergence and application of the Internet of Things technology, the problems in the management of computer labs have been significantly improved, and the application effect is particularly significant.

\section{The meaning of the Internet of Things}

The Internet of Things is an important part of the new generation of information technology and an important stage of development in the information age. The Internet of Things is extended and extended by the client to exchange information and communication between items and articles. It is widely used in network fusion through intelligent sensing, recognition technology and communication sensing technology. Therefore, the Internet of Things is another development and innovation after the development of the Internet. It expands the function and practicability of the Internet of Things itself. Based on the Internet, the client is scientifically and reasonably extended quickly, rather than the Internet of Things. It would be better to compare the Internet of Things to business and applications, so that items and items can communicate with each other.

\section{Management mode of traditional computer lab}

In the past, the teaching process of computer labs, teachers will apply teaching software, give students the explanation of computer operation technology, and also be able to record the students' learning situation in detail. However, in the teaching, a teacher should guide more than 60 students. When students have doubts about the knowledge they have learned, they hope to get a detailed explanation from the teacher. Because there are more students and the class time is limited, the teacher's Answers often fail to meet the needs of students.

In the past, in the computer lab management process, the usage record and maintenance time of 
each computer existed in the form of cardboard records, but the purchase time, maintenance time, faults and software and hardware replacement time of each computer Etc., most students are not able to fill in the records in a timely manner, so the integrity of the information of each computer cannot be guaranteed, and thus the computer lab administrators cannot obtain the corresponding information through the computer usage records, which cannot be guaranteed. Troubleshoot and maintain the computer on time, causing failures during the use of the computer, affecting student learning and learning quality. In addition, the information of cardboard is difficult to keep, and it is prone to loss or loss, which has a serious impact on the work of computer lab managers.

Computer lab administrators should regularly check the computer, but most of the lab managers take turns on duty, and only one or two administrators can test all the computers at a time, and because of the lab's computer the frequency of use is higher every day, and the problems and faults are different. For example, switch machine failure, hardware damage, virus intrusion, etc. In this case, the workload of the manager is large and complicated, which may result in the management not having Sufficient time to repair and maintain each computer and troubleshooting, thus delaying the teaching time and quality of teaching.

In the management of the computer lab environment, due to the high frequency of use of computer labs and the large flow of personnel, the impact on the laboratory environment is also very large. If this problem cannot be solved well, it will be serious. Affect the normal operation of computer hardware and frequent failures, such as power supply, motherboard damage, blue screen of the machine, poor power supply contact, power failure, etc., which will affect students' class hours and quality of learning.

In computer lab management, security issues have always been a concern for students and teachers. The laboratory receives more classes every day, and the flow of people is large. Therefore, safety problems frequently occur, which brings great difficulties to the safety management of laboratories. Safety issues include: student and laboratory items lost, improper operation caused by fire, etc. These are the safety hazards of the laboratory.

\section{Internet-based computer lab management}

The Internet of Things is applied to computer labs, which can realize the mutual communication between people, things and things, and even people and things, and can effectively establish information control between people and things in the system. Complete the information collection. At the same time, it can accurately identify it, implement positioning and tracking, manage computer labs through Internet of Things technology, optimize the deficiencies in manual laboratory management, and meet the requirements of computer lab management.

The most important thing in the management of computer labs is to ensure that the laboratory can effectively complete daily teaching. Through the application of the Internet of Things, it is more intelligent in computer lab management.

The laboratory can issue a unique RPID card to each student. The student can use the card to access the control program through the entrance of the laboratory. Students without a card cannot enter, so the teacher can use the card to query and record. Student attendance and learning.

After the application of the Internet of Things technology, you can obtain a variety of terminal data, not only can master the teaching content and teaching methods, but also better monitor all the information in the classroom, including: the student's learning situation and performance in the classroom. The Internet of Things can also analyze and detect the acquired information reasonably, and summarize the teaching experience and existing deficiencies. Therefore, it can also promote the improvement of teachers' teaching methods. It can be seen that effective monitoring of laboratory teaching can not only improve the teaching technology of teachers, but also promote students' self-consciousness and improve teaching quality.

The Internet of Things can comprehensively record students' classroom learning information. If students have insufficient knowledge or forgetting knowledge, students can re-learn by finding their own classroom learning information records, so that they can solve the students' learning process well. In the loopholes, we can review the knowledge we have learned, so as to improve students' 
understanding and mastery of key points and difficulties, and improve the quality of learning.

The Internet of Things can effectively maintain the system in the computer lab, realize its management in management, and improve the management quality.

Install RFID tags on each computer to record the basic information of the computer, including: purchase date, instructions for use, operating precautions, hardware configuration, and maintenance information, so that the computer information can be updated in real time, even if the computer is replaced. The hardware and accessories can also back up and store the information in the RFID tag. The device will automatically save and record the data, so that the information can be stored for a long time. It is also possible to record information on the items under test to prevent leakage and error occurrence, and to optimize the time-consuming processing of item information by hand.

The computer lab receives a high frequency of teaching every day, and it has a heavier teaching task. The number of students attending the computer lab is higher every day, and the class and the age of the students are different every day. Therefore, it appears for computers. Failure, it is difficult for laboratory administrators to find the main source and cause of major failures and affect the maintenance of the computer. Applying the Internet of Things mode, RFID can be installed on the computer, and the computer can record the usage record of the computer through the information record in the RF chip, so that the cause of the failure can be detected in time, and the fault and maintenance caused can be effectively recorded. In this way, you can control the computer.

The computer lab will provide students with a variety of media presentation teaching and computer operations, which can effectively improve the quality of students' learning. However, such a teaching mode has a high demand for the laboratory environment. In the application process of the Internet of Things, the sensor that senses light can fully meet this demand. The administrator only needs to follow the feedback information of the sensor, and the appropriate pair The light in the laboratory is adjusted to meet the teaching requirements.

In the computer lab, according to the sensor, the administrator can adjust the learning content according to the set laboratory curriculum, reduce the time required for the students and teachers to adjust in the computer, and give the computer the execution instructions and other related operations to improve effectiveness. In addition, the feedback information obtained by the sensor ensures the cleanliness of the laboratory to a certain extent.

The safety of computer labs mainly includes two categories: laboratory equipment safety and fire safety. In order to effectively protect the safety of teaching equipment and fire safety in the laboratory, monitors, access control and far-infrared alarms should be installed in each classroom. The monitoring system can connect the management of the laboratory with the local area network, and the monitoring video can be effectively saved, which is convenient for monitoring the occurrence of security accidents. The application of the access control can confirm the identity information of the students and teachers. Those who do not have permission can not enter the room, and give an alarm reminder in time to attract attention. The far-infrared alarm can automatically detect the room temperature in the laboratory. If an open flame or smoke occurs, an alarm will be automatically given to promptly remind and mitigate the loss, thus ensuring safety.

\section{Conclusion}

At present, with the continuous reform of China's education model, laboratory teaching has become a necessary mode for teaching in various universities, and has received extensive attention from the society. Computer is one of the necessary skills for talents in society, and it is the most basic condition for innovative thinking to serve the society. Therefore, it has become one of the key talents trained by universities in the country. The past computer lab management model has been unable to meet the needs of modern management. At present, the Internet of Things management model is the most widely used in computer lab management, and the effect is very significant. The intelligent management mode of the Internet of Things is far superior to the manual management mode of the past, and the management efficiency is greatly improved. The mode is somewhat: saving manpower, physics and financial resources. At the same time, this management mode is also an opportunity and challenge in teaching management. It is hoped that the computer lab 
management mode of the Internet of Things can provide a good technical platform for education and scientific research in China, improve the quality of teaching services, and promote the development of scientific research in China.

\section{References}

[1] Zeng Yimei, Feng Hui, Shi Guojun. Exploration of computer lab management mode based on internet of things in medical colleges[J]. Electronic World, 2014(04): 8.

[2] Xu Fang, Liu Jie. Research and Practice of Computer Professional Tuning in Higher Vocational Education under the Background of Internet of Things Industry[J]. Computer CD-ROM Software and Application, 2014, 17(16): 43-44.

[3] Ling Min. Talking about the Key Technology of Internet of Things and the Application of Computer Internet of Things[J]. Wireless Interconnect Technology, 2015(24): 56-57.

[4] Zhang Wei, Man Xiaolin. Research on Computer Network Teaching Reform Practice Based on Internet of Things Environment[J]. Computer Knowledge and Technology, 2016, 12(06): 271-272.

[5] Li Diqiu. Thoughts on the Reform of Computer Network Technology Specialty in Higher Vocational Education in the Age of Internet of Things[J]. Fujian Computer, 2016, 32(07): 72+81.

[6] Jiao Yang, Wang Zhuo, Li Shouhong. Intelligent Computer Laboratory Management System Based on ZigBee Internet of Things [J]. Radio and TV University, 2016(03): 25-27.

[7] Zhong Mingyao, Wen Yan. Design of Intelligent Computer Laboratory Management System Based on Internet of Things[J]. Wireless Interconnect Technology, 2016(18): 129-130.

[8] Ding Hui. Research on Computer Experiment Center Management Based on Internet of Things[J]. Electronic Technology and Software Engineering, 2015(12): 14.

[9] Mao Si. Talking about the Key Technology of Internet of Things and the Application of Computer Internet of Things[J]. Software, 2018, 39(06): 189-191+208.

[10] Mao Ligang. Application of Computer Information Technology in Network Data Management under the Background of Internet of Things[J]. Information Communication, 2018(07): 135-136.

[11] Huang Tingpei, Zheng Qiumei. Exploration of Teaching Reform of Computer Composition Principles in Internet of Things Engineering[J]. Education and Teaching Forum, 2016(50): 103-104.

[12] Zhou Wei. Exploration and Practice of Teaching and Training of Internet of Things Technology in Computer Network Technology of Secondary Vocational Schools[J]. Network Security Technology and Application, 2017(03): 97+99. 